\title{
Transplante autólogo de conjuntiva com uso de cola de fibrina em pterígios primários
}

\author{
Conjunctival autologous transplantation using fibrin glue in primary pterygium
}

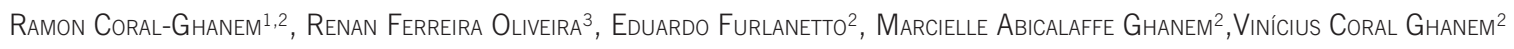

\section{RESUMO}

Objetivo: Avaliar a taxa de recidiva e complicações pós-operatórias em transplante autólogo de conjuntiva com uso de cola de fibrina para adesão do enxerto conjuntival em pterígios primários. Secundariamente, comparar os resultados obtidos aos de um grupo submetido à mesma técnica cirúrgica, com uso de suturas.

Métodos: Foram incluídos prospectivamente 106 olhos de 100 pacientes operados de pterígio com uso de cola de fibrina e retrospectivamente 58 olhos de 51 pacientes operados com uso de suturas. Avaliaram-se: idade, localização, grau e invasão do pterígio e complicações pós-operatórias. Os pacientes foram acompanhados por um período mínimo de cinco meses.

Resultados: Dentre os 106 olhos operados com uso de cola, 12 (11,3\%) apresentaram recidiva, sendo $4(3,8 \%)$ conjuntivais e $8(7,5 \%)$ corneanas. Entre os fatores estudados, somente a idade foi estatisticamente inferior nos casos recidivados (média de 34,6 vs. 43,7; $P=0,033$ ). 0 tempo até a recidiva variou de 1,6 a 13,1 meses (média de 4,4). Dentre as recidivas corneanas, dois olhos apresentaram invasão além do limbo de até $0,5 \mathrm{~mm}$ e seis olhos de 0,6 a $1,0 \mathrm{~mm}$. Nenhum olho foi submetido a reoperação. Outras complicações incluíram: formação de granuloma transitório em três casos; descolamento parcial ou retração do enxerto em três; e "dellen" em um. Dentre os 58 olhos operados com suturas, $15(25,9 \%)$ apresentaram recidiva, sendo 8 conjuntivais $(13,8 \%)$ e 7 corneanas $(12,1 \%)$. O tempo até a recidiva variou de 0,7 a 9,7 meses (média de 4,5). Um caso de recidiva corneana foi reoperado com transplante de membrana amniótica. A taxa de recidiva conjuntival foi estatisticamente inferior nos casos em que se utilizou cola do que naqueles com sutura $(P=0,023)$, porém não se observou esta diferença em relação à recidiva corneana $(P=0,232)$.

Conclusão: $\mathrm{O}$ uso da cola de fibrina, como método alternativo à sutura, traz bons resultados cirúrgicos e pequena incidência de complicações. Apesar de resultar em menor taxa de recidiva conjuntival, esta técnica não parece diminuir significativamente a incidência de recidiva corneana.

Descritores: Pterígio; Transplante autólogo; Conjuntiva; Adesivo tecidual de fibrina; Recidiva

\section{ABSTRACT}

Purpose: To assess the rate of recurrence and complications after primary pterygium removal with conjunctival autograft using fibrin tissue adhesive. Secondarily, to compare these results with a retrospective series that underwent the same surgery using sutures.

Methods: A hundred and six eyes of 100 patients who underwent surgery with fibrin glue were prospectively studied, while 58 eyes of 51 patients who underwent surgery with sutures were retrospectively evaluated. Data included: age, gender, eye involved, location, grade and pterygium invasion and postoperative complications. Patients were followed for at least 5 months.

Results: Among 106 eyes undergoing surgery with fibrin glue, 12 (11.3\%) had recurrence, including 4 (3.8\%) conjunctival and 8 (7.5\%) corneal. Mean age was statistically inferior in the recurrence cases compared to others (mean of 34.6 vs. 43.7; $P=0.033$ ). The time for recurrence ranged from 1.6 to 13.1 months (mean of 4.4). Among the corneal recurrences, 2 eyes had invasion beyond the limbus of up to $0.5 \mathrm{~mm}$ and 6 eyes from 0.6 to $1.0 \mathrm{~mm}$. No eye underwent reoperation. Other complications included: transitory granuloma formation in 3 cases, partial graft detachment or slippage in 3 and dellen in 1 . In the suture group, 15 eyes (25.9\%) had recurrence, including 8 conjunctival (13.8\%) and $7(12.1 \%)$ corneal. The time for recurrence ranged from 0.7 to 9.7 months (mean 4.5 months). The conjunctival recurrence rate was statistically inferior in the glue group compared to the suture $(P=0.023)$, however no statistically significant difference was observed in relation to corneal recurrence $(P=0.232)$.

Conclusion: The use of fibrin glue as an alternative to sutures in pterygium surgery was associated with good results and few complications. Despite a decrease in conjunctival recurrence rates, this technique does not appear to significantly decrease corneal recurrences.

Keywords: Pterygium; Transplantation, autologous; Conjunctiva; Fibrin tissue adhesive; Recurrence
Estudo realizado no Hospital de Olhos Sadalla Amin Ghanem - Joinville (SC), Brasil. ${ }^{1}$ Médico, Departamento de Oftalmologia, Faculdade de Medicina, Universidade de São Paulo - USP - São Paulo (SP), Brasil.

${ }_{2}^{2}$ Médico, Hospital de Olhos Sadalla Amin Ghanem - Joinville (SC), Brasil.

3 Acadêmico do Curso de Medicina, Pontifícia Universidade Católica do Paraná - PUC/PR Curitiba (PR), Brasil.

Os autores declaram não possuir interesse financeiro nos produtos referidos no estudo e declaram ser o trabalho inédito.

Não houve auxílio financeiro para realização deste estudo.

Endereço para correspondência: Ramon Coral Ghanem. Rua Fernando de Noronha, 225 - Apto. 901 - Joinville (SC) - CEP 89203-072 - E-mail: ramonghanem@gmail.com

Recebido para publicação em 07.08.2009

Última versão recebida em 19.03.2010

Aprovação em 01.07.2010

\section{INTRODUÇÃO}

0 pterígio é uma neoformação conjuntival de caráter fibrovascular e formato triangular ou trapezoidal que se desenvolve a partir da conjuntiva em direção à córnea, geralmente situado no setor nasal ${ }^{(1)}$. Em seu tratamento sintomático, drogas anti-inflamatórias e lubrificantes têm um papel significativo. Porém, por não contribuírem para a cura, o tratamento definitivo é, invariavelmente, cirúrgico(1). Atualmente o transplante autólogo de conjuntiva vem se tornando a técnica cirúrgica mais utilizada para pterígio, devido a sua menor taxa de recorrência pós-operatória e menor risco de complicações ${ }^{(1-3)}$. Tais benefícios, no entanto, são contrapostos aos inconvenientes inerentes a esta técnica: maior tempo de cirurgia - devido ao grande número de suturas necessárias para a fixação do enxerto no leito episcleral - e a sensação de corpo estranho referida pelo paciente no período pós-operatório(1). 
Neste contexto, o uso da cola de fibrina para a fixação do enxerto após a exérese do pterígio, como substituto às suturas, tem demonstrado vantagens como menor tempo cirúrgico e menor inflamação pós-operatória(4-10). A cola de fibrina é uma solução constituída basicamente por fibrinogênio, fator XIII da coagulação, plasminogênio, fibronectina plasmática e trombina humana e simula os estágios finais da cascata de coagulação(4-10)

O presente estudo tem como objetivo principal avaliar a taxa de recidiva e outras complicações pós-operatórias em transplante autólogo de conjuntiva com o uso de cola de fibrina em pterígios primários. Como objetivo secundário, estes resultados foram comparados a um grupo retrospectivo em que se utilizou a mesma técnica, com o uso de suturas.

\section{MÉTODOS}

\section{Pacientes e acompanhamento}

Foram incluídos neste estudo 164 olhos de 151 pacientes submetidos à cirurgia de pterígio primário no Hospital de Olhos Sadalla Amin Ghanem, em Joinville-SC, entre julho de 2004 e julho de 2008. Os procedimentos foram realizados por dois médicos da equipe (RCG e VCG), experientes na execução desta cirurgia, utilizando em todos os procedimentos a mesma técnica. A cirurgia foi indicada quando o pterígio ameaçava o eixo visual ou ocasionava sintomas como irritação frequente, hiperemia conjuntival ou sensação de corpo estranho. Todos os pacientes manifestaram vontade de submeter-se a cirurgia e assinaram o termo de consentimento informado.

Foram avaliados prospectivamente 106 olhos de 100 pacientes operados de pterígio com a técnica de transplante autólogo de conjuntiva com uso de cola de fibrina, durante o período de 11/10/2006 a 28/08/2008. O acompanhamento médio destes pacientes foi de 10,4 $\pm 3,0$ meses (de 5,2 a 16,2). O cirurgião RCG realizou 83 cirurgias (78,3 \%) e VCG, 23 (21,7\%). Dois olhos necessitaram de suturas no intraoperatório além do uso da cola para fixação do enxerto e foram excluídos do estudo. Em análise posterior, os resultados foram comparados a um grupo de 58 olhos de 51 pacientes estudados retrospectivamente, submetidos a transplante autólogo de conjuntiva com uso de suturas para fixação do enxerto, durante o período de 10/07/2004 a 11/10/2006. O acompanhamento médio destes pacientes foi de $13,8 \pm 7,2$ meses (de 5,1 a 29). Neste grupo, o cirurgião VCG realizou 52 cirurgias (89,7\%) e RCG, 6 (10,3\%). O cirurgião RCG iniciou suas atividades no Hospital Sadalla Amin Ghanem em 2006. Avaliaram-se: idade, localização, grau e invasão do pterígio, existência de complicações pós-operatórias e seu manejo.

O pterígio foi classificado morfologicamente como atrófico (grau 1), intermediário (grau 2) e carnoso (grau 3), segundo a classificação de $\operatorname{Tan}^{(3)}$. A invasão do pterígio foi medida na lâmpada de fenda por sua extensão corneana a partir do limbo. Os pacientes foram acompanhados por um período mínimo de cinco meses. Considerou-se recidiva corneana (recidiva verdadeira) o crescimento de tecido fibrovascular atingindo a superfície da córnea, ultrapassando o limbo ${ }^{(1)}$. Quando a recidiva limitou-se à conjuntiva, esta foi chamada de recidiva conjuntival.

O estudo foi aprovado pelo Comitê de Ética e Pesquisa do Hospital de Olhos Sadalla Amin Ghanem e não houve nenhum interesse financeiro ou patrocínio na realização deste estudo.

\section{TÉCNICA CIRÚRGICA}

A técnica utilizada tomou como base a descrita por Kenyon et al. ${ }^{(2)}$, com algumas modificações. Iniciou-se com anestesia tópica de uma gota de cloridrato de proximetacaína 0,5\% (Anestalcon ${ }^{\circledR}$, Alcon) seguida de três gotas de cloridrato de tetracaína 1\%, mais uma gota de cloridrato de fenilefrina 0,1\% (Anestésico ${ }^{\circledR}$, Aller- gan) a cada 5 minutos. Assepsia foi feita com iodopovidona 10\%, seguida da colocação do blefarostato e campos estéreis.

Com o olhar direcionado de forma a expor o pterígio, injetou-se de 1 a $2 \mathrm{ml}$ de cloridrato de lidocaína 2\% (Xylestesin ${ }^{\circledR}$, Cristália) com vasoconstritor no espaço subconjuntival próximo à base do pterígio. Em seguida, com tesoura de conjuntiva, removeu-se o corpo do pterígio em plano único (conjuntiva + cápsula de Tenon) até perto de sua base, distante do limbo cerca 5 a $6 \mathrm{~mm}$ do limbo, seguido de sua cabeça. Posteriormente se procedeu delaminacão do tecido fibrovascular residual sobre a córnea, com bisturi lâmina 15 e cauterização minimizada, procurando preservar a vascularização do leito escleral.

Logo após, realizou-se infiltração de anestésico subconjuntival na conjuntiva bulbar superior e procedeu-se à confecção do enxerto doador, de tamanho proporcional à área receptora, separando-o da cápsula de Tenon no sentido do fórnice para o limbo. O enxerto conjuntival livre foi transplantado para o leito receptor, respeitando-se a origem limbo/limbo.

A fixação do enxerto na área receptora foi feita por meio da cola de fibrina Beriplast $P^{\circledR}$ (Aventis Behring GmbH, Marburg, Alemanha). Este material constitui um sistema de formação de selante de fibrina que simula a fase final do processo de coagulação do sangue. O kit inclui dois conjuntos: o primeiro é composto por um frasco de solução de fibrinogênio e fator XIII da coagulação, um frasco de solução de aprotinina e um dispositivo de transferência; o segundo contém um frasco de solução de trombina, um frasco de solução de cloreto de cálcio e outro dispositivo de transferência. Tais componentes são misturados nas proporções adequadas em um processo de reconstituição. A solução resultante deve ser aplicada entre o leito episcleral e o enxerto conjuntival.

Na maioria dos casos, primeiro aplicou-se a solução de trombina + cálcio (frasco azul) no enxerto conjuntival, já posicionado sobre a córnea com a face estromal para cima; em seguida, aplicou-se a solução de fibrinogênio + fator XIII + aprotinina (frasco vermelho) sobre o leito episcleral e procedeu-se rapidamente ao posicionamento do enxerto conjuntival no leito. Constatou-se melhor adesão quando o posicionamento se completava dentro de cerca de 10 segundos.

Outro fator importante identificado para a adesão do enxerto foi a remoção completa da cápsula de Tenon subjacente a ele. Quando a aplicação do selante foi feita sobre restos de Tenon, observou-se nítida instabilidade do enxerto, o que não ocorreu quando foi aplicado sobre a episclera nua e seca. Ao final do procedimento, após um período mínimo de dois minutos da aplicação do selante, a adesão das extremidades do enxerto foi checada e, nos casos de instabilidade ou adesão insuficiente, nova aplicação de selante foi realizada no local.

Nos pacientes em que se utilizaram suturas, realizou-se a fixação com 5 a 7 pontos simples de fio seda 8.0 ancorados na episclera, para serem removidos após 15 dias. Ao final da cirurgia, foi aplicada pomada de ciprofloxacina associada à dexametasona (Cilodex ${ }^{\circledR}$, Alcon) e realizado curativo oclusivo, mantido por 24 horas.

No pós-operatório foi prescrito colírio de ciprofloxacina com dexametasona (Cilodex ${ }^{\circledR}$, Alcon) de 4/4 horas por 15 dias, seguido de dexametasona (Maxidex ${ }^{\circledR}$, Alcon) de $6 / 6$ horas com diminuição gradativa pelo período de mais 4 semanas. Os pacientes foram orientados a retornar no $1^{\circ}$ e $15^{\circ}$ dias e após 1,2 , 6 e 12 meses. Nos olhos que apresentavam sinais de risco de recidiva (inflamação conjuntival, granuloma ou proliferação fibrovascular) foram aplicadas injeções subconjuntivais com 0,2 ml de acetato de dexametasona $8 \mathrm{mg} / \mathrm{ml}$ (Decadronal ${ }^{\circledR}$, Ache) ou 5-fluorouracil $25 \mathrm{mg} / \mathrm{ml}$ (Ophthalmos). As avaliações pós-operatórias foram realizadas pelos respectivos cirurgiões, que decidiram sobre a necessidade de nova intervenção. 


\section{Análise estatística}

Para a análise estatística, os dados foram incluídos em uma planilha no programa Microsoft Excel 2007 (Microsoft Corp, Redmond, EUA), que foi utilizado juntamente com o programa SPSS 13.0 (SPSS Inc, Chicago, EUA) para o sistema "Windows". Utilizaram-se os testes $t$ de Student não pareado, Qui-quadrado de Pearson e teste exato de Fisher. Para variáveis contínuas sem distribuição normal foi utilizado o teste de Mann-Whitney. Um valor $P<0,05$ foi considerado estatisticamente significante.

\section{RESULTADOS}

\section{Pacientes e ACompanhamento}

Foram estudados prospectivamente 106 olhos de 100 pacientes, 55 do sexo feminino e 45 do sexo masculino. Em todos os olhos, o pterígio era nasal e primário. No pós-operatório foram aplicadas injeções subconjuntivais em 8 olhos (7,5\%) com Decadronal e em 6 olhos (5,7\%) com 5-fluorouracil. Os dados demográficos e pré-operatórios encontram-se na tabela 1.

\section{Recidivas}

Dentre os 106 olhos, 12 (11,3\%) apresentaram recidiva após a cirurgia. $O$ tempo até a recidiva variou de 1,6 a 13,1 meses (média de 4,4). Houve 4 recidivas conjuntivais $(3,8 \%)$ e $8(7,5 \%)$

Tabela 1. Dados demográficos e pré-operatórios dos pacientes submetidos a transplante autólogo de conjuntiva com uso de cola de fibrina $(n=106)$ ou suturas $(n=58)$

\begin{tabular}{|c|c|c|c|}
\hline Característica & Grupo cola & Grupo sutura & $P$ \\
\hline $\begin{array}{l}\text { № olhos / № pacientes } \\
\text { Sexo, n (\%) }\end{array}$ & $106 / 100$ & $58 / 51$ & - \\
\hline Masculino / feminino & $45(45,0 \%) / 55(55,0 \%)$ & $24(47,1 \%) / 28(54,9 \%)$ & $0,684^{*}$ \\
\hline $\begin{array}{l}\text { Idade (anos) } \\
\text { Média } \pm \text { DP } \\
\text { (mín. - máx.) }\end{array}$ & $\begin{array}{c}42,6 \pm 13,9 \\
19 \text { a } 77\end{array}$ & $\begin{array}{c}49,3 \pm 14,7 \\
22 \text { a } 79\end{array}$ & $0,005^{* *}$ \\
\hline $\begin{array}{l}\text { Olho acometido, n (\%) } \\
\text { Direito / esquerdo }\end{array}$ & $53(49,5 \%) / 54(50,5 \%)$ & $32(55,2 \%) / 26(44,8 \%)$ & $0,624^{*}$ \\
\hline $\begin{array}{l}\text { Grau do pterígiot } \\
\text { Grau } 1 \\
\text { Grau } 2 \\
\text { Grau } 3\end{array}$ & $\begin{array}{l}14(13,2 \%) \\
50(47,2 \%) \\
42(39,6 \%)\end{array}$ & $\begin{aligned} 6 & (10,3 \%) \\
31 & (53,4 \%) \\
21 & (36,3 \%)\end{aligned}$ & $0,717^{*}$ \\
\hline $\begin{array}{l}\text { Invasão do pterígio (mm } \\
\text { Média } \pm \text { DP } \\
\text { (mín. - máx.) }\end{array}$ & $\begin{array}{l}2,3 \pm 1,1 \\
0,5 \text { a } 6,0\end{array}$ & $\begin{array}{l}2,4 \pm 1,0 \\
0,5 \text { a } 5,0\end{array}$ & $0,507^{* * *}$ \\
\hline $\begin{array}{l}\text { Seguimento } \\
\text { Média } \pm \text { DP } \\
\text { (mín. - máx.) }\end{array}$ & $\begin{array}{l}10,4 \pm 3,0 \\
5,2 \text { a } 16,2\end{array}$ & $\begin{array}{l}13,8 \pm 7,2 \\
5,1 \text { a } 29,0\end{array}$ & $0,035^{* * *}$ \\
\hline
\end{tabular}

$\mathrm{DP}=$ desvio padrão; ${ }^{*}=$ teste do qui-quadrado; ${ }^{* *}=$ teste t não-pareado; ${ }^{* * *}=$ teste de Mann-Whitney; $\dagger=$ classificação de Tan

Tabela 2. Características dos olhos operados com uso de cola de fibrina que apresentaram recidivas $(n=12)$

\begin{tabular}{lccc}
\hline Características & Recidiva $\mathbf{n = 1 2}$ & Sem recidiva $\mathbf{n = 9 4}$ & $\boldsymbol{P}$ \\
\hline Idade (média em anos) & 34,6 & 43,7 & $0,033^{*}$ \\
Sexo, $\mathrm{n}(\%)$ & $6(50 \%) / 6(50 \%)$ & $39(41 \%) / 55(59 \%)$ & $0,309^{* *}$ \\
$\quad$ Masculino / feminino & & & \\
Olho acometido, $\mathrm{n}(\%)$ & $6(50 \%) / 6(50 \%)$ & $47(50 \%) / 47(50 \%)$ & $1,000^{* *}$ \\
Direito / esquerdo & 2,2 & 2,3 & $0,599^{* * *}$ \\
Grau do pterígio (média em mm) & 2,2 & 2,3 & $0,859^{* * *}$ \\
Invasão do pterígio (média em mm) & 9,6 & 10,5 & $0,349^{* * *}$ \\
Seguimento (médio em meses) & $1 / 12=8,3 \%$ & $5 / 94=5,3 \%$ & $0,132^{* *}$ \\
Complicações no enxerto (n, médio) & & & \\
\hline
\end{tabular}

${ }^{*}=$ teste $\mathrm{t}$ não-pareado; ${ }^{* *}=$ teste do qui-quadrado; ${ }^{* * *}=$ teste de Mann-Whitney corneanas. Dentre as recidivas corneanas, 2 olhos apresentaram invasão além do limbo de até 0,5 mm e 6 olhos de 0,6 a . Nenhum olho apresentou recidiva corneana maior do que 1,0 mm. Durante o período de acompanhamento, neolho foi submetido a reoperação, parte por ausência de

A ção clínica, parte por opção do paciente.

\section{OUtRAS COMPLICAÇÕES}

Foram observadas as seguintes complicações pós-operatórias: formação de granuloma transitório em 3 casos (2,7\%); descolamento parcial ou retração do enxerto em 3 casos $(2,7 \%)$ e "dellen" em 1 caso (0,9\%).

Uma paciente teve descolamento do enxerto conjuntival após esfregar o olho operado no $4^{\circ}$ dia após a cirurgia. Ela relatou o ocorrido ao cirurgião através de contato telefônico. 0 enxerto foi reposicionado e suturado no mesmo dia, porém evoluiu com necrose parcial e recidiva corneana de $1,0 \mathrm{~mm}$ algumas semanas após.

\section{GRUPO COM SUTURAS}

No grupo com suturas, dentre os 58 olhos avaliados, 15 $(25,9 \%)$ apresentaram recidiva após a cirurgia. O tempo até a recidiva variou de 0,7 a 9,7 meses (média de 4,5 meses). Houve 8 recidivas conjuntivais $(13,8 \%)$ e $7(12,1 \%)$ corneanas (Tabela 3). Um caso de recidiva corneana foi reoperado com transplante de membrana amniótica.

Outras complicações pós-operatórias incluíram: retração ou deslocamento do enxerto em 6 olhos (10,2\%), soltura de pontos em 2 olhos (3,4\%), formação de "dellen" em 1 olho $(1,7 \%)$ e de granuloma em 1 olho $(1,7 \%)$.

\section{DISCUSSÃO}

O uso da cola de fibrina na cirurgia de pterígio representa um avanço inquestionável, por tornar o procedimento mais rápido para o cirurgião e a recuperação mais confortável para o paciente ${ }^{(4-10)}$. Não existem, entretanto, na literatura nacional, outros estudos avaliando os resultados do transplante autólogo de conjuntiva com uso de cola de fibrina na cirurgia do pterígio.

Este estudo incluiu os primeiros 100 pacientes submetidos à cirurgia de pterígio com cola de fibrina na instituição e demonstra que a transição para o uso da cola pode ser feita com pequena incidência de complicações e taxa de recidiva similar ou menor do que com uso de suturas.

A taxa de recidiva corneana com uso de cola neste estudo foi de 7,5\% e com uso de suturas foi de $12,1 \%$. Apesar de clinicamente inferior, esta diferença não foi estatisticamente significante. A taxa de recidiva conjuntival, entretanto, foi estatisticamente inferior com uso de cola do que com suturas, o que pode ser explicado pela menor inflamação conjuntival quando a cirurgia é realizada sem suturas ${ }^{(10)}$. 
Tabela 3. Taxa de recidiva após transplante autólogo de conjuntiva em pterígios primários com uso de cola de fibrina ou suturas

\begin{tabular}{lccc}
\hline $\begin{array}{l}\text { Tipo } \\
\text { de recidivas }\end{array}$ & $\begin{array}{c}\text { Grupo com } \\
\text { cola (n=106) }\end{array}$ & $\begin{array}{c}\text { Grupo com } \\
\text { suturas (n=58) }\end{array}$ & $\boldsymbol{P}$ \\
\hline Recidiva conjuntival & $4(3,8 \%)$ & $8(13,8 \%)$ & $0,023^{*}$ \\
Recidiva corneana & $8(7,5 \%)$ & $7(12,1 \%)$ & $0,232^{* *}$ \\
Total & $12(11,3 \%)$ & $15(25,9 \%)$ & $0,016^{* *}$ \\
\hline
\end{tabular}

${ }^{*}=$ teste exato de Fisher; ${ }^{* *}=$ teste do qui-quadrado

Outros estudos descreveram taxas similares de recidiva corneana às aqui encontradas, tanto com uso de cola biológica como com suturas. Koranyi et al. demonstraram recorrência em $8 \%$ dos olhos operados com transplante autólogo e uso de cola de fibrina e em $20 \%$ dos com sutura ${ }^{(4)}$. Bahar et al. observaram recidiva em $11,9 \%$ dos olhos operados com uso de cola e 7,7\% nos olhos operados com uso de suturas ${ }^{(6)}$. Farid e Pirnazar observaram 3,7\% nos olhos operados com cola e $20 \%$ nos com sutura $^{(11)}$. Karalezli et al. observaram $4 \%$ de recidiva no grupo com cola e $12 \%$ no grupo com suturas ${ }^{(7)}$.

A taxa de recidiva é certamente influenciada por fatores como: técnica cirúrgica individual, localização geográfica da população estudada, reação inflamatória do paciente, idade, grau e invasão do pterígio, cuidados no pós-operatório com exposição à radiação ultravioleta e outros fatores agressivos ambientais (vento, poeira, fumaça, calor, etc.).

O tempo de seguimento e a definição de recorrência empregada também influenciam as taxas de recidiva descritas nos diferentes estudos ${ }^{(1-3,12)}$. No presente estudo, o tempo de seguimento e a idade eram significativamente diferentes entre os dois grupos estudados, o que pode ter influenciado nas taxas de recorrência observadas. No grupo com cola, observou-se que os pacientes com recorrência eram significativamente mais jovens que os outros. O tempo médio para ocorrência da recidiva foi de 4,4 meses, o que equivale ao de outros estudos, que demonstraram períodos entre 3 e 6 meses ${ }^{(4,11,13)}$.

Entre as outras complicações, a mais temida é o descolamento ou a retração do enxerto, o que ocorreu em 2,7\% dos pacientes operados com cola. Em uma paciente atribuiu-se a recidiva do pterígio ao descolamento traumático do enxerto, ocorrido nos primeiros dias após a cirurgia. Para evitar a ocorrência de casos como o relatado, ressalta-se a importância de evitar o trauma local nas primeiras duas semanas após o procedimento. Em outros estudos ${ }^{(5,7,11,13)}$, a incidência de descolamento do enxerto com o uso de cola variou de $0 \%$ a $9 \%$.

Um dos fatores relacionados a ainda modesta adesão dos cirurgiões ao uso da cola de fibrina é seu alto custo. Um kit de $0,5 \mathrm{ml}$ de cola de fibrina custa aproximadamente oito vezes o preço de um envelope de fio mononylon 10-0 ou quatro vezes o preço de um envelope de fio de poliglactina 8-0 (Vicryl), o que limita sua utilização. Por outro lado, entretanto, deve-se considerar que, com um kit de 0,5 ml de cola, pode-se realizar no mesmo dia entre 10 e 15 cirurgias, o que torna seu custo inferior ao das suturas.

Os autores do presente estudo preferem agrupar as cirurgias para somente um ou dois dias por mês e somente durante os meses de outono e inverno, quando a radiação ultravioleta é menor ${ }^{(1)}$. Isto possibilita a realização de várias cirurgias no mesmo dia, tornando o uso da cola de fibrina financeiramente viável. Segundo orientações do fabricante, uma vez reconstituídas, as soluções de trombina e fibrinogênio permanecem estáveis por 24 horas em temperatura entre $15^{\circ} \mathrm{C}$ e $25^{\circ} \mathrm{C}$, se estocadas na embalagem externa estéril.

Nas condições deste estudo ficou demonstrado que o uso da cola de fibrina, como método alternativo à sutura, na realização do transplante autólogo de conjuntiva na cirurgia do pterígio, traz bons resultados cirúrgicos e pequena taxa de complicações. Apesar de resultar em menores índices de recidiva conjuntival, contudo, esta técnica não demonstrou uma redução estatisticamente significante na incidência de recidiva corneana. Constatou-se que serão necessários estudos avaliando um maior número de pacientes, para conhecer de modo mais aprofundado o comportamento da cola de fibrina na taxa de recidiva após a cirurgia de pterígio.

\section{REFERÊNCIAS}

1. Hirst LW. The treatment of pterygium. Surv Ophthalmol. 2003;48(2):145-80. Review.

2. Kenyon KR, Wagoner MD, Hettinger ME. Conjunctival autograft transplantation for advanced and recurrent pterygium. Ophthalmology. 1985;92(11):1461-70.

3. Tan DT, Chee SP, Dear KB, Lim AS. Effect of pterygium morphology on pterygium recurrence in a controlled trial comparing conjunctival autografting with bare sclera excision. Arch Ophthalmol. 1997;115(10):1235-40. Erratum in: Arch Ophthalmol. 1998;116(4):552.

4. Koranyi G, Seregard S, Kopp ED. Cut and paste: a no suture, small incision approach to pterygium surgery. Br J Ophthalmol. 2004;88(7):911-4. Comment in: Br J_Ophthalmol. 2005;89(3):392; author reply 392.

5. Uy HS, Reyes JM, Flores JD, Lim-Bon-Siong R. Comparison of fibrin glue and sutures for attaching conjunctival autografts after pterygium excision. Ophthalmology. 2005;112(4):667-71.

6. Bahar I, Weinberger D, Gaton DD, Avisar R. Fibrin glue versus vicryl sutures for primary conjunctival closure in pterygium surgery: long-term results. Curr Eye Res. 2007;32(5):399-405

7. Karalezli A, Kucukerdonmez C, Akova YA, Altan-Yaycioglu R, Borazan M. Fibrin glue versus sutures for conjunctival autografting in pterygium surgery: a prospective comparative study. Br J Ophthalmol. 2008;92(9):1206-10.

8. Kheirkhah A, Casas V, Sheha H, Raju VK, Tseng SC. Role of conjunctival inflammation in surgical outcome after amniotic membrane transplantation with or without fibrin glue for pterygium. Cornea. 2008;27(1):56-63.

9. Ozdamar Y, Mutevelli S, Han U, lleri D, Onal B, Ithan B, et al. A comparative study of tissue glue and vicryl suture for closing limbal-conjunctival autografts and histologic evaluation after pterygium excision. Cornea. 2008;27(5):552-8.

10. Srinivasan S, Dollin M, McAllum P, Berger Y, Rootman DS, Slomovic AR. Fibrin glue versus sutures for attaching the conjunctival autograft in pterygium surgery: a prospective observer masked clinical trial. Br J Ophthalmol. 2009;93(2):215-8

11. Farid M, Pirnazar JR. Pterygium recurrence after excision with conjunctival autograft: a comparison of fibrin tissue adhesive to absorbable sutures. Cornea. 2009; 28(1):43-5.

12. Lani AH, Lani LA. Transplante autólogo de conjuntiva em pterígio primário. Arq Bras Oftalmol. 2005;68(1):99-102

13. Ayala M. Results of pterygium surgery using a biologic adhesive. Cornea. 2008; 27(6):663-7. 